Jurnal Interpretasi Hukum | ISSN: 2746-5047

Vol. 2, No. 3-Desember 2021, Hal. 602-606| Tersedia online di

https://www.ejournal.warmadewa.ac.id/index.php/juinhum

DOI: https://doi.org/10.22225/juinhum.2.3.4144.602-606

\title{
KEWENANGAN KEJAKSAAN DALAM MELAKUKAN PENAHANAN TERHADAP PELAKU TINDAK PIDANA UJARAN KEBENCIAN DI SOSIAL MEDIA
}

\author{
Louis Muda Adam Gesi Radja, I Nyoman Gede Sugiartha, Ni Made Sukaryati Karma \\ Fakultas Hukum, Universitas Warmadewa, Denpasar-Bali, Indonesia \\ louismuda98@gmail.com, nyomansugiartha14@gmail.com, sukariati64@gmail.com
}

\begin{abstract}
Abstrak
Kewenangan adalah apa yang disebut kekuasaan formal, kekuasaan berasal dari kekuasaan legislatif (diberi oleh undang undang) atau dari kekuasaan eksekutif administratif. Kewenangan yang biasanya terdiri dari beberapa wewenang adalah kekuasaan terhadap segolongan orang tertentu atau kekuasaan terhadap suatu bidang pemerintahan. Tujuan penelitian ini untuk menganalisa pengaturan kewenangan kejaksaan dalam melakukan penahanan terhadap pelaku tindak pidana ujaran kebencian di sosial media serta hambatan kejaksaan dalam melakukan penahanan pelaku tindak pidana ujaran kebencian di sosial media. Metode Penelitian yang aplikasikan pada penelitian ini yaitu penelitian hukum normatif dengan pendekatan masalah melalui perundangundangan serta pendekatan konseptual. Teknik pengumpulan bahan hukum dilakukan dengan cara yaitu studi kepustakaan. Sumber bahan hukum yang digunakan berupa sumber bahan hukum primer, sekunder, dan tersier. Setelah bahan hukum telah terkumpul, maka selanjutnya akan akan diolah dan dianalisis menggunakan metode pengolahan bahan hukum secara sistematis dan disajikan secara deskriptif. Hasil penelitian mengungkapkan bahwa bahwa Kewenangan kejaksaan yaitu diatur dalam kitab undang-undang hukum acara pidana, undangundang kewenangan kejaksaan yang mencangkup beberapa undang-undang antara lain Undang-undang No. 16 Tahun 2004 yang mengatur tentang kejaksaan, sehingga dari undang-undang tersebut dapat dipastikan tentang hak dan wewenang kejaksaan agar penegak hukum khususnya kejaksaan dapat melakukan penahanan sesuai dengan aturan yang sudah berlaku, sehingga tidak ada penyalahgunaan wewenang yang dilakukan oleh penegak hukum khususnya Jaksa dan sebagaimana mestinya kejaksaan wajib mewujudkan kesetaraan terhadap seluruh warga negara Indonesia yang sedang terjerat kasus pidana, perdata maupun yang lainya.
\end{abstract}

Kata Kunci: Akibat Hukum, Kewenangan, Tindak Pidana

\begin{abstract}
Authority is what is called formal power, power comes from legislative power (given by law) or from executive administrative power. Authority, which usually consists of several powers, is power over a certain group of people or power over an area of government. The purposes of this study are to analyze the arrangement of the prosecutor's authority in detaining the perpetrators of hate speech crimes on social media and the prosecutor's obstacles in detaining the perpetrators of hate speech crimes on social media. The research method applied in this research is normative legal research with a statutory and a conceptual approach. The technique of collecting legal materials is done by means of a literature study. The of used are primary, secondary, and tertiary sources of legal materials. After the legal material has been collected, it will then be processed and analyzed using the method of processing legal materials systematically and presented descriptively. The results of the study reveal that the prosecutor's authority is regulated in the criminal procedural law code, the prosecutor's authority law. Which includes several laws, among others, Law no. 16 of 2004 which regulates the prosecutor's office, so that from the law it can be ascertained about the rights and powers of the prosecutor so that law enforcers, especially the prosecutor's office, can make detentions in accordance with the rules that have been in force, so that there is no abuse of authority by law enforcers, especially prosecutors and as The prosecutor's office should be obliged to realize equality for all Indonesian citizens who are being entangled in criminal, civil and other cases.
\end{abstract}

Keywords: Legal Consequences, Authority, Crime

\section{PENDAHULUAN}

Bangsa Indonesia adalah termasuk Negara demokrasi paling besar di bumi ini. Untuk menelaah makna kemerdekaan berpendapat, sebaiknya dilakukan pengkajian dari etimologinya (kebebasan). Dilohat dari sisi etimologisnya, kemerdekaan ialah kondisi terbebas serta tidak tertindih. Sedangkan pendapat biasanya dimaknai sebagai pemikiran atau ide. Mempunyai pendapat artinya mengungkapkan ide atau menyatakan pemikiran. Maka, kemerdekaan berpendapat ialah suatu kondisi 
di mana tidak ada tindihan untuk mengungkapkan ide atau gagasan, dengan tercatat ataupun tidak tercatat. Dilihat dari pasal 14 huruf c belum dapat memastikan apakah kejaksaan dapat melakukan penahanan bagi pelaku tindak pidana ujaran kebencian. Kejaksaan hanya dapat melakukan penahanan jika dilihat dari Pasal 21 ayat (4) kitab undang-undang hukum acara pidana.

Adanya persoalan yang diduga sudah terjadi pelanggaran peraturan sesuai pasal yakni persoalan Ujaran kebencian yang dilakukan oleh satu tokoh aktivis yang bernama I Gede Ari Astina. Dalam kasus ini Jerinx Memposting sebuah foto dan memberikan sebuah caption yang isinya (IDI) Ikatan Dokter Indonesia bangga menjadi kacung (WHO) World Health Organization, dengan Postingan itu Ari Astina dikenakan Pasal 28 ayat 2 UU ITE yang dimana Ari Astina Menebarkan Kebencian kepada masyarakat bahwa IDI adalah Kacung WHO. Pada Proses penuntutan Ari Astina ditahan dan tidak dibiarkan bebas, meskipun Pelaku sendiri sudah menempuh jalur penangguhan, dan sampai tahap itu justru jaksa sangat berwenang untuk melakukan sebuah penahanan. Maka pasal yang dikenakan untuk pelaku yaitu masa kurungan maksimal 6 tahun Penjara, dan jika kita merujuk kepada kewenangan kejaksaan dalam melakukan penahanan, jaksa sangat amat berwenang menahan jika pasal yang disangkakan di atas 4 tahun penjara.

Adapun penelitian sebelumnya dari Disurya (2019) dalam proses peradilan pidana, aparat penegak hukum baik Polisi, Jaksa Penuntu Umum, maupun Hakim harus tetap memperhatikan tujuan hukum itu sendiri yaitu harus memperhatikan keadilan, kemanfaatan, dan menjamin kepastian hukum. Adapun menurut Irawan et al., (2020) mengatakan bahwa dalam tuntutannya, kejaksaan penuntut umum menerapkan Pasal 28 Ayat 2 serta Pasal 45 Ayat 2 serta KUHAP sebagai pedoman hukum acara dalam melaksanakan tugas dan kewenangannya. Sedangkan Utami et al., (2021) berpendapat bahwa kejaksaan merupakan salah satu subsistem yang bekerja sama dalam sistem peradilan pidana dan dalam hal ini mempunyai peran dengan proses dijatuhkannya pidana penjara sebagai jaksa penuntut umum. Dari fenomena tersebut maka dilakukannya penelitian yang bertujuan untuk menganalisa pengaturan kewenangan kejaksaan dalam melakukan penahanan terhadap pelaku tindak pidana ujaran kebencian di sosial media serta hambatan kejaksaan dalam melakukan penahanan pelaku tindak pidana ujaran kebencian di sosial media.

\section{METODE PENELITIAN}

Metode Penelitian yang dipakai terhadap penelitian ini yaitu penelitian hukum normatif, pendekatan masalah melalui perundang-undangan, serta pendekatan konseptual. Teknik Pengumpulan Bahan Hukum untuk penelitian ini, penulis mengumpulkan bahan-bahan Hukum dengan cara yaitu studi kepustakaan yaitu teknik pengumpulan bahan hukum melalui cara dengan mengumpulkan sejumlah jenis bahan bacaan yakni buku-buku literatur, ketentuan undang-undang, artikel-artikel hukum, serta bacaan-bacaan yang lain. Ada beberapa sumber hukum dari bahan hukum primer serta sekunder. Bahan hukum primer yang mencakup Undang-undang Dasar Negara Republik Indonesia Tahun 1945, Undang-undang No. 11 Tahun 2008 Tentang Informasi dan Transaksi Elektronik, Undang-undang No. 8 tahun 1981 tentang kitab Undang-undang Hukum acara pidana, Undang-undang No. 16 tahun 2004 Tentang Kejaksaan. mengenai Kesejahteraan. Adapun bahan hukum sekunder yang dikutip dari kajian kepustakaan yang meliputi membaca beberapa buku, jurnal-jurnal hukum, serta artikel yang berhubungan mengenai kewenangan kejaksaan dalam melakukan penahanan pada tahap penuntutan. Sedangkan bahan hukum tersier pendukung serta sumber hukum sekunder serta sumber hukum primer dimana sumber hukum tersier yakni sumber hukum berupa KBBI maupun kamus bahasa latin serta bahasa Inggris. Setelah bahan hukum telah terkumpul, maka bahan hukum tersebut akan akan diolah dan dianalisis menggunakan metode pengolahan bahan hukum secara sistematis dan hasilnya disajikan secara deskriptif.

\section{HASIL DAN PEMBAHASAN}

\section{Pengaturan Kewenangan Kejaksaan Dalam Melakukan Penahanan Terhadap Pelaku Tindak Pidana Ujaran Kebencian di Sosial Media}

Kejaksaan adalah Lembaga penegakan hukum yang berwenang melakukan penahanan dalam tahap penuntutan jika pasal yang disangkakan kepada sebuah pelaku tindak pidana ujaran kebencian diatas 5 tahun tahanan hal tersebut mengacu kepada pasal 21 ayat (4) kitab undang-undang hukum acara pidana (Simarmata, 2011). Atas kewenangan kejaksaan untuk melaksanakan sebuah tugas, fungsi, 
serta wewenang diluar dari pengaruhnya terhadap kewenangan pemerintahan, serta kontrol kewenangan yang lain (Kristiana, 2006). Hal ini bermakna negara dapat melindungi jaksa ketika melaksanakan pekerjaan profesinya yang tidak ada gertakan, penghambat, provokasi, rayuan yang salah ataupun pengungkapan yang tidak terbukti kebenarannya, dengan atas sebuah tanggapan pidana, perdata, atau lainnya.

Kejaksaan satu di antara institusi penegakan hukum diharuskan agar melakukan peran yang lebih didalam memenuhi tugas profesionalnya, yang tunduk serta mematuhi terhadap janji ataupun sumpah, beserta kode etik jaksa, yang mana menjadikan petunjuk maupun pijakan bagi mereka yang menjalankan tugas keseharian sebagai jaksa (Supriyadi, 2006). Dari segi normatif bisa diketahui di dalam peraturan-peraturan UU Kejaksaan RI. Kekuasaan kejaksaan seperti yang tertera di Pasal 30 yakni:

a) Melakukan sebuah penuntutan.

b) Melaksanakan sebuah penetapan hakim dan putusan pengadilan yang telah mendapatkan kekuatan hukum yang utuh.

c) Menjalankan pengawasan terhadap suatu pelaksanaan putusan pidana bersyarat, putusan pidana pengawasan, dan putusan lepas bersyarat.

d) Melakukan penyidikan terhadap tindak pidana tertentu berdasarkan undang-undang Melengkapi berkas perkara tertentu dan untuk dapat melakukan pemeriksaan tambahan sebelum dilimpahkan ke pengadilan yang Pada pelaksanaannya dikoordinasikan dengan penyidik (Akub \& Badaru, 2012).

\section{Hambatan Kejaksaan Dalam Melakukan Penahanan Pelaku Tindak Pidana Ujaran Kebencian di Sosial Media}

Hubungan Kejaksaan sebagai instansi penuntut umum dengan pihak yang bertalian dengan polisi menjadi lembaga penyidik sudah memiliki jalinan kerjasama yang baik. Menyelesaikan perkara pidana berdasarkan proses yang ditetapkan di dalam KUHAP. Namun, kejaksaan juga memiliki persoalan yakni sisa pekerjaan yang belum diputuskan perkaranya, dan sebagian besar kasus yang belum dituntaskan itu terbanyak ditemukan ketika sampai tahapan pra-penuntutan. Karena terbatasnya jumlah penyidik yang mencari tersangka, dapat terjadi inkoordinasi di antara pihak kejaksaan serta kepolisian dan apabila menemui sesuatu yang sulit serta memakan waktu yang lama, Pasal 1 ayat 1 KUHAP. Di Dalam pelaksanaan penahanan tersangka harus dipenuhi 2 persyaratan ataupun penyebab, yakni persyaratan obyektif serta subyektif, yaitu:

1. Syarat Subyektifitas

2. Syarat Objektivitas

Penahanan merupakan satu diantara yang teristimewa dari hukum acara pidana, yang mana ketentuan hukum acara pidana mengesampingkan beberapa asas yang berlaku umum, misalnya asas penahanan yang berkaitan atas hak asasi manusia. Hal ini berdasarkan pernyataan Hamzah (2012) semestinya tindakan ditahan dilaksanakan jika amat diperlukan untuk proses penahanan. Dalam terjadinya suatu perkara yang terkena kepada siapapun sudah kodratnya ia mendapatkan hak-hak konstitusi sebagai warga negara. dan tidak menjadi hal yang biasa bila kejaksaan mempunyai hambatan-hambatan dalam melakukan penahanan adalah sebuah hak penangguhan yang dimiliki setiap warga yang terjerat kasus hukum sehingga membuat kejaksaan mempunyai hambatan dalam melakukan penahanan pada tahap penuntutan, yang dimana sebuah penangguhan dilakukan pada tahap 2 yaitu kejaksaan.

Hambatan-hambatan penangguhan untuk ditahan tidak terlepas dari perlindungan serta persyaratan untuk pelaksanaan proses penawanan. Kendala kesatu, berhubungan dengan prosedur yang responsibilitas serta keterbukaan yang buruk dan terkadang merupakan hambatan didalam proses ditangguhkannya penawanan, dikarenakan tidak adanya pelaporan tentang nilai besaran penjaminan meskipun pada surat perjanjian dinyatakan tetapi baru menjadikan tugas diantara aparat yang memberi penundaan untuk ditahan terhada yang bersalah atau yang menjadi tersangka tidak dengan terdapatnya pelaporan yang dilaksanakan dengan terbuka dan karena sistem pertanggungjawaban penyampaian yang tidak begitu tertib, utamanya berkaitan dengan nilai uang untuk proses ditangguhkannya penawanan yang semestinya disetorkan serta dilaporkan ke kas panitera, menjadikan penundaan penawanan serta penjaminan uang kurang transparan. Kendala kedua ialah tidak efektifnya 
pengontrolan atas terdakwa didalam pemenuhan syarat penundaan penawanan sehingga menyebabkan terdakwa sering melarikan diri. Untuk itu diperlukan koordinasi bersama pihak kepolisian untuk melakukan pengawasan supaya terdakwa menyadari sedang dalam pengawasan serta pengendalian. Kendala ketiga, kurangnya pengamanan untuk hakim, juga menjadi kekurangan di dalam putusan penundaan penawanan, yang berpengaruh terhadap putusan hakim, meskipun hal ini tidak berujung terhadap putusan hakim yang tidak adil. Kendala keempat adalah panitera terkadang melakukan kelalaian serta tidak pernah memberikan tanda terima uang penjaminan yang diberikan oleh tersangka atau yang menjadi kuasa hukum, terkadang uang penjaminan yang diberikan untuk penundaan penawanan yang acapkali tidak pernah kembali pada pihak yang memberi meskipun kemudian terdakwa diumumkan telah bersalah oleh pengadilan.

Penangguhan penahanan yaitu mengeluarkan tersangka atau terdakwa dari penahanan sebelum batas waktu penahanan berakhir (Harahap, 2002). Terjadinya penangguhan penahanan seolah-olah didasarkan pada "bentuk kontrak" atau "perjanjian" dalam hubungan perdata. Itu sebabnya cenderung untuk mengatakan terjadinya penangguhan penahanan berdasarkan "perjanjian" antara orang tahanan dengan pihak instansi yang menahan. Orang tahanan berjanji akan melaksanakan dan memenuhi syarat dan jaminan yang ditetapakan instansi yang menahan, dan sebagai "imbalan" pihak yang menahan mengeluarkan dari tahanan dengan menangguhkan penahanan (Soesilo, 2003). Terkait alasan penangguhan penahanan tidak disinggung di dalam Pasal 31 Kitab undang-undang hukum acara pidana maupun dalam penjelasan pasal tersebut. Kalau begitu ditinjau dari segi yuridis, mengenai alasan penangguhan dianggap tidak relevan untuk dipersoalkan. Persoalan bagi hukum dalam penangguhan berkisar pada masalah "syarat" dan "jaminan penangguhan". tetapi, sekalipun undang-undang tidak menentukan, alasan penangguhan, dan memberi kebebasan dan kewenangan penuh kepada instansi yang menahan untuk menyetujui atau tidak menangguhkan, sepatutnya instansi yang bersangkutan mempertimbangkan dari sudut kepentingan dan ketertiban umum dengan jalan pendekatan sosiologis, psikologis dan preventif. karena itu, kebebasan dan kewenangan menangguhkan penahanan, jangan semata-mata bertitik tolak dari sudut persyaratan dan jaminan yang ditetapkan, tapi juga harus mengkaji dan mempertimbangkan lebih dalam dari sudut yang lebih luas.

\section{SIMPULAN DAN SARAN}

\section{Simpulan}

Pengaturan Kewenangan Kejaksaan dalam melakukan penahanan merupakan suatu hal perlu diketahui dan harus ada, guna untuk menghindari Penyalahgunaan kewenangan yang dilakukan oleh kejaksaan. khususnya melakukan tindakan penahanan terhadap pelaku tindak pidana. Kejaksaan dipimpin Jaksa agung yang dipilih langsung oleh Presiden dan bertanggung jawab langsung kepada Presiden, tetapi meskipun Jaksa agung Dipilih langsung oleh Presiden Jaksa Agung harus tetap bersifat Adil dalam menjalankan Kewenangannya Sebagai Jaksa. Adapun hambatan Kejaksaan dalam melakukan penahanan Merupakan kendala yang dialami kejaksaan saat melakukan Investigasi terhadap sebuah kasus yang sedang berjalan, dalam hambatan tersebut jelas bahwa sebuah hak penangguhan setiap warga negara yang sedang terjerat hukum adalah sebuah hambatan yang dialami jaksa untuk melakukan Penahanan pada tahap penuntutan itu sendiri. Waktu Masa Penahanan pada tahap Penuntutan adalah 20 hari dan jika dibutuhkan waktu yg lebih lama lagi bisa diperpanjang menjadi 40 hari dan sudah maksimal.

\section{Saran}

Pemerintah Dan lembaga yang berwenang untuk membuat aturan tentang kewenangan kejaksaan agar lebih spesifik lagi di atur dalam undang-undang kewenangan kejaksaan. Dikarenakan pada undangundang kejaksaan tidak spesifik diatur tentang kewenangan kejaksaan dalam penahanan pada tahap penuntutan. Yang dimana kejaksaan harus merujuk kepada kitab undang-undang hukum acara pidana guna untuk melakukan penahanan supaya tidak terjadi pelanggaran hak asasi manusia yang menahan pelaku tindak pidana dengan tidak menggunakan dasar hukum yang kuat. Pelaku Tindak pidana ujaran kebencian seharusnya memperhatikan akibat hukum yang harus dihadapi setelah melakukan ujaran kebencian tersebut. Karna hanya karna memberikan cuitan yang singkat di sosial media pelaku terjerat tindak pidana ujaran kebencian yang dimana itu sangat amat tidak berkesan dan hal yang tidak 
diharapkan baik oleh masyarakat ataupun oleh lembaga penegak hukum yang berwenang untuk mengurus kasus semacam ini.

\section{DAFTAR PUSTAKA}

Akub, M. S., \& Badaru, B. (2012). Wawasan Due Proces of Law Dalam Sistem Peradilan Pidana. Rangkang Education, Jakarta.

Disurya, R. (2019). Praktik Penegakan Hukum pada Tindak Pidana Ujaran Kebencian (Hate Speech). Justici, 11(2), 1-11.

Hamzah, A. (2012). Hukum Acara Pidana Indonesia. Sinar Grafika, Jakarta.

Harahap, Y. (2002). Pembahasan Permasalahan Kitab Undang-undang Hukum Pidana dan Penerapanya. Sinar Grafika, Jakarta.

Irawan, Baharuddin, H., \& M, N. F. (2020). Efektivitas Penuntutan Terhadap Tindak Pidana Ujaran Kebencian (Hate Speech): Studi Kejaksaan Negeri Makassar. Journal of Lex Generalis (JLS), $1(5), 683-697$.

Kristiana, Y. (2006). Independensi Kejaksaan Dalam Penyidikan Korupsi. Citra Aditya Bakti, Bandung.

Simarmata, B. (2011). Pengawasan Terhadap Pelaksanaan Penahanan Menurut Kitab Undang-undang Hukum Acara Pidana. Mimbar Hukum, 23(1), 191-209.

Soesilo, R. (2003). Tugas Kewajiban dan Kewenangan Penyidik, Jaksa, Hakim. Sinar Grafika, Jakarta.

Supriyadi. (2006). Etika Tanggung Jawab Profesi Hukum di Indonesia. Sinar Grafika, Jakarta.

Utami, Y. P., Lembong, R. R., \& Muaja, H. S. (2021). Tindak Pidana Menyebarkan Berita Bohong dan Menyesatkan yang Mengakibatkan Kerugian Konsumen Dalam Transaksi Elektronik. Lex Crimen, 10(2), 34-44. 